\title{
Improving Children Moral Values through Personal Social Health
}

\section{Economics Education}

\section{Dr/Hala Seliet \\ President of the Egyptian British Education Association -London}

\section{Rational and background}

Since the implementation of Every Child Matters in 2007, schools have a duty to promote their pupils' wellbeing. But the way this is done is left to the individual school. Some opt to provide dedicated wellbeing or Seal lessons dealing with specific social and emotional skills, while others encourage pupils to take part in extra-curricular lessons to try to develop so-called soft skills without the pressures of academic assessment.

According to Mick Waters, the director of curriculum at the Qualifications and Curriculum Authority, PSHE teachers need to make sure that, as children move towards adulthood, they are "confident as individuals, responsible as citizens and successful as learners".

\section{Ways to Inculcate Moral Values in Your Child}

1. Practice What You Preach

2. Narrate Personal Experiences

3. Reward Good Behaviour

4. Communicate Effectively

5. Monitor Television and Internet Use 


\title{
Moral Values for Children to Lead a Great Life
}

\author{
1. Respect \\ 2. Family \\ 3. Adjusting and Compromising \\ 4. Helping Mentality \\ 5. Respecting Religion \\ 6. Justice \\ 7. Honesty \\ 8. Never Hurt Anyone \\ 9. Theft
}

10. Cultivate Love for Education

\section{What Makes a Child Develop a Negative Attitude?}

If you observe your child exhibiting negative behaviour, there are chances that he may be doing so because of the following issues:

- If you have imposed too many restrictions on your child.

- If you as a parent express too much negativity.

- If you are overprotective.

- If your child is suffering from psychological issues.

- If there is a disturbed environment at home.

- If a child experiences a lot of criticism then he may become negative in life. 